\title{
The vasal fluid proteomic profile and microscopic sperm presence at time of vasectomy reversal
}

\author{
Theodore R. Saitz ${ }^{1,2}$, Kevin A. Ostrowski ${ }^{3}$, Ann Martinez Acevedo ${ }^{1}$, Jasper C. Bash ${ }^{1}$, John Klimek ${ }^{4}$, \\ Eugene F. Fuchs ${ }^{1}$, Larry L. David ${ }^{5}$, Jason C. Hedges ${ }^{1}$ \\ ${ }^{1}$ Department of Urology, Oregon Health \& Science University, Portland, OR, USA; ${ }^{2}$ Department of Surgery, Nellis Air Force Base Hospital, \\ Uniformed Services University of the Health Sciences, Nellis AFB, NV, USA; ${ }^{3}$ Department of Urology, University of Washington School of \\ Medicine, Health Sciences Building, Seattle, WA, USA; ${ }^{4}$ Proteomics Shared Resource, Oregon Health \& Sciences University, Portland, OR, USA; \\ ${ }^{5}$ Department of Chemical Physiology \& Biochemistry, Oregon Health Sciences University, Portland, OR, USA \\ Contributions: (I) Conception and design: KA Ostrowski, TR Saitz; (II) Administrative support: A Martinez Acevedo, LL David, JC Hedges; (III) \\ Provision of study materials or patients: A Martinez Acevedo, LL David, JC Hedges; (IV) Collection and assembly of data: J Cunliffe, A Martinez \\ Acevedo, JC Bash, J Klimek, TR Saitz, JC Hedges, KA Ostrowski; (V) Data analysis and interpretation: TR Saitz, J Klimek, LL David, JC Hedges, \\ JC Bash, A Martinez Acevedo; (VI) Manuscript writing: All authors; (VII) Final approval of manuscript: All authors. \\ Correspondence to: Theodore R. Saitz, MD. Department of Urology, Oregon Health \& Science University, 3303 SW Bond Avenue, CH10U, Portland, \\ OR 97239, USA. Email: trsaitz@gmail.com.
}

Background: The microscopic characteristics of vasal fluid at time of vasectomy reversal (VR) guide operative decision making and predict fertility outcomes. The proteomic profile of this vasal fluid has not been described or correlated with the microscopic fluid appearance. To characterize the vasal fluid proteome at time of VR and evaluate the variation of the vasal fluid proteome with respect to microscopic presence of sperm.

Methods: A prospective cohort study was conducted enrolling twenty-five men undergoing VR for infertility and/or pain at a University-affiliated hospital. Vasal fluid samples obtained at time of VR were grouped based on presence of sperm on light microscopy at time of VR. Proteomic profiles were generated using liquid chromatography/ tandem mass spectrometry, and MS/MS protein spectral counts compared between individuals and treatment groups, controlling for less than $5 \%$ protein false discovery rate (FDR). Proteins were matched with the human swissprot database using the Comet search engine, and categorized by Gene Ontology (GO) terms.

Results: There was large variability between the 46 vasal fluid samples collected, with 1,692 unique proteins detected. The three most abundant proteins were Lactotransferrin, Cysteine-rich secretory protein 1, A-kinase anchor protein 4 . There was no correlation between the proteome and microscopic sperm presence. Prevalent GO terms included viral process, signal transduction, innate immune response, protein folding and spermatogenesis.

Conclusions: We describe the proteome and the most common proteins in vasal fluid at time of VR. Numerable sperm, testis and epididymis specific proteins were present even in the absence of sperm on microscopy. Further evaluation is needed to determine if a protein biomarker may better guide operative decision making and predict VR fertility outcomes.

Keywords: Vasectomy reversal (VR); vasovasostomy (VV); proteomics; obstructive azoospermia

Submitted Mar 03, 2020. Accepted for publication Sep 06, 2020.

doi: $10.21037 /$ tau-20-703

View this article at: http://dx.doi.org/10.21037/tau-20-703 


\section{Introduction}

Every year in the United Sates it is estimated that over 500,000 men undergo vasectomy (1), and due to various reasons, up to $6 \%$ of these patients eventually elect to undergo vasectomy reversal (VR) (2). At the time of VR, microsurgeons evaluate both the gross and microscopic appearance of vasal fluid to determine the likelihood of secondary vasal obstruction, which influences the type of surgery to be performed and guides clinical decision making after surgery (3).

Although also common practice, consideration of the gross appearance of vasal fluid has not been significantly correlated with success of VR $(4,5)$. However, if the fluid's gross appearance is clear and copious, then vasovasostomy $(\mathrm{VV})$ is routinely performed, even in the absence of sperm (6). When whole sperm are identified, the patency rate after VV approaches $99.5 \%$ (7). The Vasovasostomy Study Group first described microscopic fluid findings, obstructive interval, and presence of sperm granuloma were associated with pregnancy rates in 1991 (8) and more recent studies have contributed to this body of evidence $(9,10)$; However, few other factors have been identified to guide practice since this time.

Over the past decade, the sperm and seminal fluid proteomes have been largely defined, including a number of proteins with altered expression in men with semen abnormalities or poorly functioning sperm (11). Several protein biomarkers have been studied as candidate biomarkers of obstructive azoospermia or to be used as a confirmatory test for post vasectomy clearance (12-14). However, the proteome of vasal fluid in post-vasectomy patients remains uncharacterized, and it is unclear if this fluid is primarily derived from the epididymis, vas deferens, or sperm.

Understanding the origins of this fluid may explain factors contributing to obstruction following VR, or the origins of post vasectomy pain syndrome. The ability to identify and correlate a sperm, testis or epididymis specific protein with patency and pregnancy rates would allow surgeons save time in the operative theater, make more informed management decisions and better counsel patients on expected outcomes. In addition, identifying a biomarker protein to delineate non-obstructive azoospermia (NOA) versus obstructive azoospermia $(\mathrm{OA})$ will allow for optimal counseling and treatment of these patients compared to the current paradigm.

This study characterizes the proteomic profile of vasal fluid at time of VR and compared these findings to the gross and microscopic appearance of the fluid at this time. It also compares the proteomic profiles to the patients' associated patency and fertility outcomes. It was hypothesized that testis, epididymal and sperm specific proteins would be relatively less abundant in samples with no sperm present on microscopy. The following article is presented in accordance with the STROBE reporting checklist (available at http://dx. doi. org/10. 21037/tau-20-703).

\section{Methods}

A prospective cohort study at a single academic center was conducted after approval by from the Oregon Health and Science University Institutional Review Board (FWA00000161; IRB00000471) and all patients provided informed consent. The study was conducted in accordance with the Declaration of Helsinki (as revised in 2013). Patients who underwent VR for pain or fertility reasons were included, while patients who did not provide permission, who had suspected NOA or who's bilateral samples could not be properly collected, stored or processed were excluded. In men who underwent unilateral VR for pain a unilateral sample was collected. Vasal fluid samples at time of VR were collected from consecutive patients post-vasectomy between the years 2015 to 2016 . The patent's age, obstructive interval, indication for procedure, and procedure performed [VV or Vasoepididymostomy (VE)] were recorded. The patient's status of patency and pregnancy at time of follow up were also analyzed. Postoperative patency was defined as the presence of motile sperm on at least one semen analysis and clinical pregnancies were determined by either review of electronic medical records or phone survey response.

During the VR samples were expressed from the cut end of the vas and collected in sterile glass capillary tubes. In patients who underwent VE, additional fluid from the epididymis was not analyzed. The gross appearance of the sample was quantified as clear, opalescent or creamy/pasty. The microscopic appearance of the fluid was quantified as having motile sperm, non-motile whole sperm, sperm parts, or no sperm. For analysis, samples were grouped into one of two groups: microscopic presence of whole sperm (either motile or non-motile) and/or sperm parts versus no sperm on microscopy at time of VR. We determined these groupings would be most likely to detect a difference in sperm, testis and epididymal derived proteins based on current understanding of the post vasectomy obstructive 
Table 1 Patient characteristics

\begin{tabular}{lc}
\hline Characteristics & Data \\
\hline Median age & 39.5 years (IQR 35-42 years) \\
Median time to reversal & 4.6 years (IQR 2-12.5 years) \\
Mean follow up & 35.9 months (range 23-40 months) \\
Number vasovasostomy & $42 / 46(91.3 \%)$ \\
Number & $2 / 46(4.4 \%)$ \\
vasoepididymostomy & $2 / 46(4.4 \%)$ \\
Number vasectomy &
\end{tabular}

$I Q R$, interquartile range.

process. Vasal samples were also taken from patients at time of vasectomy for controls in a similar fashion and run in a discovery analysis to optimize sample preparation. These samples were not included in the final analysis.

\section{Statistical analysis}

Researchers completing the proteomic and statistical analysis of the fluids were blinded to the gross and microscopic characteristics of the samples to prevent bias. For proteomic and statistical analysis, all samples were extruded from sterile collection tubes, dispersed in buffer, a protein assay performed, samples reduced/ alkylated, and proteins digested by overnight incubation with trypsin. Proteomic profiles were generated using liquid chromatography/tandem mass spectrometry as previously described (15), except using a single dimensional chromatographic separation with $90 \mathrm{~min}$ of data collection and $10 \mu \mathrm{g}$ of peptide injected per sample. Proteins were identified using a human swissprot database (UniProt Consortium) and Comet search engine (16), while controlling protein false discovery rate (FDR) at or below $1.2 \%$ as previously described (17). Identified proteins were then categorized by Gene Ontology (GO) terms and numbers of assigned MS/MS spectra (spectral counts) to each protein used to estimate differences in relative protein abundance (18). Differential Expression was assessed using Bioconductor edgeR package (Bioconductor Open Source Software for Bioinformatics) with a multipletesting correction included to control the FDR for test of differential protein abundance as previously described (19). Recruitment, collection and analysis was stopped after interim analysis demonstrated our current results supporting the null hypothesis.

\section{Results}

A total of 46 vasal fluid samples from 25 patients were collected. Of patients enrolled, 56\% (14/25) underwent VR for fertility reasons, while 36\% (9/25) underwent VR for pain and $8 \%(2 / 25)$ were vasectomy controls. Patient characteristics can be seen in Table 1. Median patient age was 39.5 years old (IQR 35-42 years old). Median time to VR, or the mean obstructive interval, was 4.6 years (IQR $2-12.5$ years). Patients were followed in our andrology clinic with a mean follow up time of 35.9 months (range, 23-40 months). Regarding the gross appearance of vasal fluid at time of VR, 29.5\% (13/44) of samples had clear fluid, $47.7 \%$ (21/44) had opalescent fluid and $22.7 \%$ (10/44) had creamy/pasty fluid. With respect to microscopic appearance of samples, motile whole sperm were present in $36 \%$ of samples, non-motile whole sperm were present in $41 \%$ of samples and sperm parts were present in $7 \%$. Thus, $84 \%$ of samples contained sperm or sperm parts. Sperm and/or sperm parts were absent in only $16 \%$ of samples. Based on the surgeon's clinical decision making paradigm $91.3 \%$ (42/46) of testicular units underwent VV and 4.4\% $(2 / 46)$ of testicular units underwent VE. The remaining $4.4 \%(2 / 46)$ of testicular units were vasectomy controls.

On proteomic analysis, a total of 1,692 proteins were identified by at least two unique peptides and at a FDR of $1.2 \%$ (please see supplementary files for complete list of proteins detected, GO terms, pathway reports, and edgeR analysis Available at: https://cdn.amegroups.cn/static/applic ation/9031b1c97015ed6de67 ccf8cbfc0b5fe/tau-20-703-01. xlsx; https://cdn.amegroups.cn/static/application/deec701c 85c116f07d7ab63fc4a5181b/tau-20-703-02.xlsx). Excluding major serum or erythrocyte proteins introduced by blood contamination during surgery, the top 10 vasal proteins by abundance were: Lactotransferrin, A-kinase anchor protein 4, Cysteine-rich secretory protein 1, Extracellular matrix protein 1, Clusterin, Actin, Maltase-glucoamylase, Epididymal secretory protein E1, WAP four-disulfide core domain protein 2, and Galectin-3-binding protein (Table 2). Dynein proteins were relatively absent in all samples, while maltase-glucoamylase, a transmembrane intestinal protein was relatively abundant.

Numerous human secretory and inflammatory proteins were detected in all samples, with no significant difference based on the gross appearance of the sample. Significant differences were observed in sperm derived proteins between clear versus creamy samples, with epididymal sperm binding protein 1 , clathrin heavy chain 1 , and fatty 
Table 2 Spectral counts of proteins of interest and most prevalent proteins

\begin{tabular}{|c|c|c|c|c|c|}
\hline & \multicolumn{3}{|c|}{ Average spectral counts } & $P$ Value & FDF \\
\hline \multicolumn{6}{|l|}{ Proteins of interest } \\
\hline Cysteine-rich secretory protein & $113.18^{*}$ & 152.13 & 103.12 & 0.24 & 1 \\
\hline Prostaglandin-H2 D-isomerase & $28.13^{*}$ & 20.75 & 30.03 & 0.56 & 1 \\
\hline L-lactate dehydrogenase $\mathrm{C}$-chain & $16.92^{*}$ & 14.83 & 17.50 & 0.85 & 1 \\
\hline Phosphoglycerate kinase 2 & $16.75^{\star}$ & 13.85 & 17.50 & 1.00 & 1 \\
\hline Testis-Expressed sequence 101 & $6.31^{*}$ & 4.00 & 6.90 & 0.56 & 1 \\
\hline Sperm-associated antigen 11B & $1.26^{*}$ & 1.63 & 1.16 & 0.56 & 1 \\
\hline Lactotransferrin & $44,359^{\star \star}$ & $1,135.88$ & 975.06 & 0.68 & 1 \\
\hline A-kinase anchor protein- 4 & $5,173^{\star \star}$ & 112.25 & 118.32 & 0.74 & 1 \\
\hline Cysteine-Rich Secretory Protein-1 & $4,890^{* *}$ & 152.13 & 103.13 & 0.24 & 1 \\
\hline Extracellular matrix protein-1 & $3,597^{\star *}$ & 116.75 & 76.52 & 0.17 & 1 \\
\hline Clusterin & $3,430^{\star \star}$ & 58.75 & 80.06 & 0.40 & 1 \\
\hline Actin & $3,367^{* *}$ & 74.38 & 60.55 & 0.26 & 1 \\
\hline Maltase-glucoamylase, intestinal & $3,077^{\star *}$ & 92.13 & 59.16 & 0.13 & 1 \\
\hline Epididymal secretory protein E1 & $3,016^{\star *}$ & 74.50 & 66.48 & 0.59 & 1 \\
\hline
\end{tabular}

${ }^{\star}$, Average per sample; ${ }^{* \star}$, total counts. FDR, false discovery rate.

acid synthase increased in creamy samples (FDR <0.047). No significant differences in proteomic profile were observed between clear versus opalescent samples.

When samples were grouped based on microscopic presence of sperm or sperm parts compared to no sperm there was no significant difference between relative spectral counts (Figure 1). The reports of several proteins of interest can be seen in Table 2. Samples were then collated with regards to abundance of 5 previously published obstruction specific proteins and this demonstrated 272 significantly different proteins between the two groups (Figure 2).

With regards to clinical outcomes, 15 of 15 patients (100\%) who had a postoperative semen analysis demonstrated patency, as defined by millions of intact motile sperm present. Of 10 patients who reported to have attempted to achieve natural pregnancy 4 (40\%) were successful. Combining these patency and pregnancy rates allowed us to account to 17 of 23 patients (74\%) to be confirmed surgically successful. There was no correlation between patency rate or obstructive interval and proteomic profile.

\section{Discussions}

The proteomic profile of vasal fluid at time of VR has not been reported previously. The majority of vasal proteins detected are known proteins found in sperm $(20,21)$ or secreted from the epididymis (22). The vasal fluid protein composition varied significantly despite vasectomy and obstruction. This study found that sperm, testis and epididymis derived proteins were present in samples even despite the microscopic absence of sperm or sperm parts. 


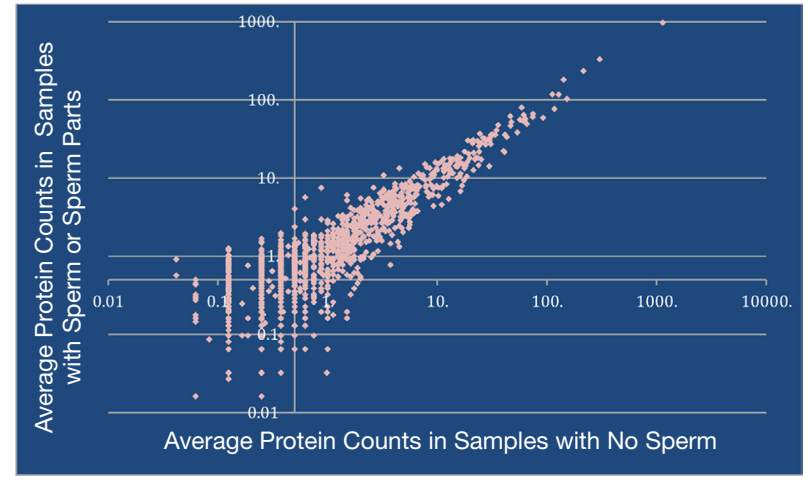

Figure 1 Vasal protein spectral counts no sperm vs. sperm present.

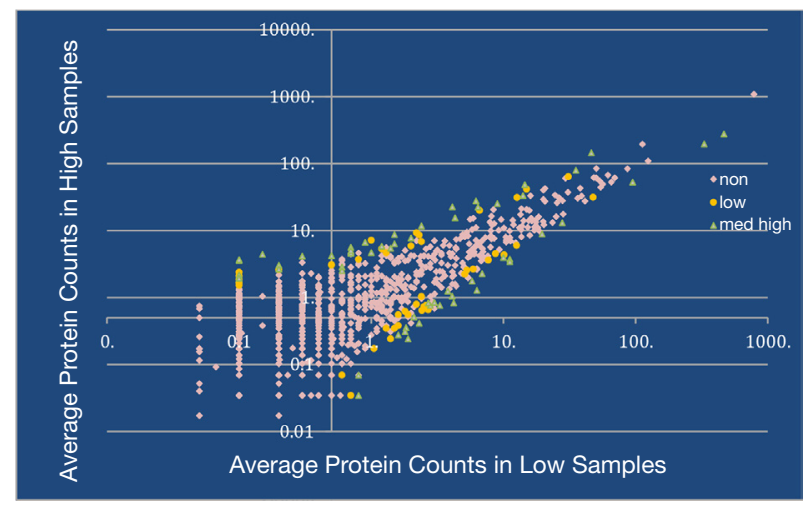

Figure 2 Vasal protein spectral counts collated with obstructive proteins.

The relative absence of dynein proteins was unexpected and may indicate the rapid degradation of this flagellar protein following vasectomy.

One of the more abundant proteins found, a transmembrane intestinal protein, Maltase-glucoamylase, suggests degradation of the vas deferens membrane components following vasectomy. Findings of elevated levels of this protein may be associated with the gross appearance of vasal fluid secondary to obstruction, although due to our small sample size we were not able to identify a correlation. Reports have found that vasal fluid produced between two obstructed vas segments in patients with segmental dysplasia of the vas deferens to be thick, white, toothpaste-like material similar to that in men with secondary epididymal obstruction. Thus, it has been concluded that this vasal "toothpaste" must be derived from vasal epithelium, not sperm $(23,24)$.

This study found that gross fluid appearance was associated with increased levels of several known sperm proteins in creamy samples when compared to clear samples. The variation in protein abundance of opalescent fluid was too great to detect significant differences compared to clear fluid. This is consistent with knowledge that pasty fluid rarely has any sperm or sperm parts seen $(25,26)$. As identification of whole spermatozoa or sperm parts in the vasal fluid at the time of VV has been positively associated with post-operative patency $(5,27)$, identifying these proteins may help decipher the changes sperm undergo after vasectomy. Further understanding of these sperm proteins will lead to better understanding of the obstructive process on sperm degradation, or may also be correlated with patency and outcomes.

Although the current clinical application of sperm and seminal fluid proteomics is limited, several studies have been conducted comparing the seminal proteomes of men with OA to those with NOA in attempts to identify potential biomarkers for obstruction $(12,13,28)$. Cysteinerich secretory protein 1 (CRISP-1) has been proposed as a biomarker of obstructive infertility, as one study found all seminal plasma samples from normospermic and NOA donors were CRISP-1 positive, whereas CRISP-1 was absent or present at low levels in samples from patients with OA (29). Another protein of interest is lipocalin-type prostaglandin D synthase (L-PGDS), as when levels were compared in men with normal semen parameters, OA, NOA, and in vasectomized men, seminal L-PGDS levels were significantly lower in men with OA (11). This study detected high levels of CRISP-1 in our samples regardless of microscopic sperm presence and we suspect levels of this protein may be altered in the process of post-vasectomy obstruction and patency. This may be due to the low rate of more proximal obstruction confirmed by a high number of patients in this study that underwent successful VR. Evaluating a higher number of obstructed patients may potentially detect a difference in biomarker proteins.

Numerous human secretory and inflammatory proteins were also detected in all samples. Although little is known about the disease process of post vasectomy pain syndrome (PVPS), it has been demonstrated that VR, either by VV or VE, can provide long-term relief from PVPS (30). Future studies are required to determine if elevated levels of these proteins are associated with PVPS and could lead to better understanding of management of this disease.

Limitations of this study include a small sample size and a limited heterogeneity of samples. This study may be improved upon by vastly increasing sample size, as there was 
large variability between the relative abundance of proteins in each sample. An improved heterogeneity of patients may also help detect potential biomarker proteins, as proximal obstruction was low in this patient population with only $4.4 \%$ undergoing $\mathrm{VE}$ based on current clinical decision making paradigms and $74 \%$ of patients demonstrating patency during the follow up period. The proteomic analysis conducted was a discovery analysis and could be more accurately analyzed with respect to specific candidate proteins in the future. Continued study of the vasal fluid proteome will contribute to a better understanding of outcomes following VR and will improve the management of OA.

\section{Conclusions}

This study characterized the proteomic profile and most abundant proteins present in vasal fluid at time of VR. The vasal fluid protein composition varies significantly despite sperm presence on light microscopy. Further evaluation is needed to determine if a potential protein biomarker is best related to sperm presence or could be used to better predict VR fertility outcomes.

\section{Acknowledgments}

We would like to acknowledge Jennifer Cunliffe, $\mathrm{PhD}$, a research associate with The Proteomics Shared Resource at Oregon Health and Science University for her time and efforts with processing samples and data collection.

Funding: None.

\section{Footnote}

Reporting Checklist: The authors have completed the STROBE reporting checklist. Available at http://dx. doi. org/10. 21037/tau-20-703

Data Sharing Statement: Available at http://dx. doi. org/10.21037/tau-20-703

Conflicts of Interest: All authors have completed the ICMJE uniform disclosure form (available at http://dx. doi. org/10.21037/tau-20-703). The authors have no conflicts of interest to declare.

Ethical Statement: The authors are accountable for all aspects of the work in ensuring that questions related to the accuracy or integrity of any part of the work are appropriately investigated and resolved. The study was conducted in accordance with the Declaration of Helsinki (as revised in 2013). The study was approved by from the Oregon Health and Science University Institutional Review Board (FWA00000161; IRB00000471) and all patients provided informed consent.

Open Access Statement: This is an Open Access article distributed in accordance with the Creative Commons Attribution-NonCommercial-NoDerivs 4.0 International License (CC BY-NC-ND 4.0), which permits the noncommercial replication and distribution of the article with the strict proviso that no changes or edits are made and the original work is properly cited (including links to both the formal publication through the relevant DOI and the license). See: https://creativecommons.org/licenses/by-nc-nd/4.0/.

\section{References}

1. Ostrowski KA, Holt SK, Haynes B, et al. Evaluation of Vasectomy Trends in the United States. Urology 2018;118:76-9.

2. Sandlow JI, Nagler HM. Vasectomy and vasectomy reversal: important issues. Preface. Urol Clin North Am 2009;36: xiii-xxiv.

3. Hayden RP, Li PS, Goldstein M. Microsurgical vasectomy reversal: contemporary techniques, intraoperative decision making, and surgical training for the next generation. Fertil Steril 2019;111:444-53.

4. Ostrowski KA, Polackwich AS, Conlin MJ, et al. Impact on Pregnancy of Gross and Microscopic Vasal Fluid during Vasectomy Reversal. J Urol 2015;194:156-9.

5. Ramasamy R, Mata DA, Jain L, et al. Microscopic visualization of intravasal spermatozoa is positively associated with patency after bilateral microsurgical vasovasostomy. Andrology 2015;3:532-5.

6. Lipshultz LI, Rumohr JA, Bennett RC. Techniques for vasectomy reversal. Urol Clin North Am 2009;36:375-82.

7. Goldstein M, Li PS, Matthews GJ. Microsurgical vasovasostomy: the microdot technique of precision suture placement. J Urol 1998;159:188-90.

8. Belker AM, Thomas AJ Jr, Fuchs EF, et al. Results of 1,469 microsurgical vasectomy reversals by the Vasovasostomy Study Group. J Urol 1991;145:505-11.

9. Kolettis PN, Burns JR, Nangia AK, et al. Outcomes for vasovasostomy performed when only sperm parts are 
present in the vasal fluid. J Androl 2006;27:565-7.

10. Smith RP, Khanna A, Kovac JR, et al. The significance of sperm heads and tails within the vasal fluid during vasectomy reversal. Indian J Urol 2014;30:164-8.

11. Barazani Y, Agarwal A, Sabanegh ES Jr. Functional Sperm Testing and the Role of Proteomics in the Evaluation of Male Infertility. Urology 2014;84:255-61.

12. Heshmat SM, Mullen JB, Jarvi KA, et al. Seminal plasma lipocalin-type prostaglandin D synthase: a potential new marker for the diagnosis of obstructive azoospermia. J Urol 2008;179:1077-80.

13. Batruch I, Smith CR, Mullen BJ, et al. Analysis of seminal plasma from patients with non-obstructive azoospermia and identification of candidate biomarkers of male infertility. J Proteome Res 2012;11:1503-11.

14. Korbakis D, Schiza C, Brinc D, et al. Preclinical evaluation of a TEX101 protein ELISA test for the differential diagnosis of male infertility. BMC Med 2017;15:60.

15. Shang F, Wilmarth PA, Chang ML, et al. Newborn mouse lens proteome and its alteration by lysine 6 mutant ubiquitin. J Proteome Res 2014;13:1177-89.

16. Eng JK, Jahan TA, Hoopmann MR. Comet: an opensource MS/MS sequence database search tool. Proteomics 2013;13:22-4.

17. Wilmarth PA, Riviere MA, David LL. Techniques for accurate protein identification in shotgun proteomic studies of human, mouse, bovine, and chicken lenses. J Ocul Biol Dis Infor 2009;2:223-34.

18. Krey JF, Wilmarth PA, Shin JB, et al. Accurate label-free protein quantitation with high- and low-resolution mass spectrometers. J Proteome Res 2014;13:1034-44.

19. Smith JR, David LL, Appukuttan B, et al. Angiogenic and Immunologic Proteins Identified by Deep Proteomic Profiling of Human Retinal and Choroidal Vascular Endothelial Cells: Potential Targets for New Biologic Drugs. Am J Ophthalmol 2018;193:197-229.

20. Bayram HL, Claydon AJ, Brownridge PJ, et al. Crossspecies proteomics in analysis of mammalian sperm

Cite this article as: Saitz TR, Ostrowski KA, Martinez Acevedo A, Bash JC, Klimek J, Fuchs EF, David LL, Hedges JC. The vasal fluid proteomic profile and microscopic sperm presence at time of vasectomy reversal. Transl Androl Urol 2020;9(5):2000-2006. doi:10.21037/tau-20-703 proteins. J Proteomics 2016;135:38-50.

21. Skerget S, Rosenow MA, Petritis K, et al. Sperm Proteome Maturation in the Mouse Epididymis. PLoS One 2015;10:e0140650.

22. Turner TT, Riley TA, Mruk DD, et al. Obstruction of the Vas Deferens Alters Protein Secretion by the Rat Caput Epididymidal Epithelium In Vivo. J Androl 1999;20:289-97.

23. Anger JT, Goldstein M. Intravasal "toothpaste" in men with obstructive azoospermia is derived from vasal epithelium, not sperm. J urol 2004;172:634-6.

24. Saitz TR, Thomas AA. Unilateral segmental dysplasia of the vas deferens. Can J Urol 2018;25:9620-2.

25. Belker AM, Konnak JW, Sharlip ID, et al. Intraoperative observations during vasovasostomy in 334 patients. J Urol 1983;129:524-7.

26. Sharlip ID, Belker AM, Konnak JW, et al. Relationship of gross appearance of vas fluid during vasovasostomy to sperm quality, obstructive interval and sperm granuloma. J Urol 1984;131:681-3.

27. Scovell JM, Mata DA, Ramasamy R, et al. Association Between the Presence of Sperm in the Vasal Fluid During Vasectomy Reversal and Postoperative Patency: A Systematic Review and Meta-analysis. Urology 2015;85:809-13.

28. Yamakawa K, Yoshida K, Nishikawa H, et al. Comparative analysis of interindividual variations in the seminal plasma proteome of infertile men with identification of potential markers for azoospermia in infertile patients. J Androl 2007;28:858-65.

29. Légaré C, Cloutier F, Makosso-Kallyth S, et al. Cysteine-rich secretory protein 1 in seminal plasma: potential biomarker for the distinction between obstructive and nonobstructive azoospermia. Fertil Steril 2013;100:1253-60.

30. Polackwich AS, Tadros NN, Ostrowski KA, et al. Vasectomy Reversal for Postvasectomy Pain Syndrome: A Study and Literature Review. Urology 2015;86:269-72. 